\title{
Firing Precision Evaluation For Unguided Artillery Projectile
}

\author{
M.E. Wessam, Z.H. Chen \\ Key Laboratory of Transient Physics \\ Nanjing University of Science \& Technology \\ Nanjing, China
}

\begin{abstract}
A case study of flow over a body of revolution was done in order to understand the variation of flow parameters past the projectile and performance of the computational code. The pre-processor software ANSYS ICEM-CFD and ANSYS FLUENT 14.5 were used to model $155 \mathrm{~mm}$ M107 artillery projectile which has been built in INVENTOR software. The flow over projectile was solved as three-dimensional flow in which angle of attack can be considered in the calculations. Aerodynamic forces and moments are computed with the computational fluid dynamic solver. A modified point mass simulation flight dynamics model is applied for the accurate prediction of trajectory of the projectile via atmospheric flight to final impact point in order to improve its precision.
\end{abstract}

Keywords-ANSYS FLUENT 14.5; CFD;aerodynamic coefficients;precision

\section{INTRODUCTION}

There are roughly four classes of techniques to predict aerodynamic forces and moments on a projectile in atmospheric flight: empirical methods, wind tunnel testing, computational fluid dynamics simulation, and spark range testing. Empirical techniques aerodynamically describe the projectile with a set of geometric properties and catalog aerodynamic coefficients of many different projectiles as a function of these features. The advantage of this method is that it is a general method applicable to any projectile. In wind tunnel testing, a specific projectile is mounted in a wind tunnel at various angles of attack with aerodynamic forces and moments measured at various Mach numbers using a sting balance. Wind tunnel testing has the obvious advantage of being based on direct measurement of aerodynamic forces and moments. In computational fluid dynamics (CFD) simulation, the fundamental fluid dynamic equations are numerically solved for a specific configuration. It is a general method that is valid for any projectile configuration. In spark range aerodynamic testing, a projectile is fired through an enclosed building. At a discrete number of points during the flight of the projectile the state of the projectile is measured using spark shadowgraphs. Spark range aerodynamic testing is considered the gold standard for projectile aerodynamic coefficient estimation [1]. If all firing conditions and characteristics of a projectile, together with atmospheric conditions can be exactly predicted, the projectile will fly on a known trajectory and hits a known target point. This trajectory is called nominal trajectory. Practically, there are always some differences between the real and predicted values; these are mainly due to manufacturing, measurement and atmospheric modeling errors [2]. The ballistic dispersion of conventional artillery shells is due to the dispersion of the initial velocity, the quadrant elevation, the angle of bearing, the projectile mass, and the initial transversal angular velocity [3]. Monte Carlo method was used to find out the optimum values of circular error probable (CEP). Therefore, there are always some errors between the positions of a desired and a real impact point; these differences make the body not to fly exactly on its nominal trajectory, and to hit defined target point. The total dispersion results mainly from; projectile mass properties, in-bore balloting, and free flight problems which are caused mainly due to wind velocity and direction (wind profile) [4]. In this work, CFD is applied to determine the aerodynamic coefficients by using a commercial CFD code called ANSYS FLUENT14.5 which solves the governing equations of the flow motion using a technique of finite volume and takes the meshed computational domain from a pre-processor program called ANSYS ICEM-CFD in which the computational domain is generated and meshed into cells. The implicit segregated structured grid solver was used in these investigations. Second order upwind discritization was used for the flow variables and turbulent viscosity equations. The aim of the present work is to evaluate and improve the firing precision of unguided spinning projectile by evaluating CEP.

\section{COMPUTATIONAL METHOD}

\section{A. Model Geometry}

Fig. 1 shows the solid model and main dimensions of the test projectile. The full scale $155 \mathrm{~mm}$ artillery projectiles was generated in INVENTOR software and modeled in CFD simulations, in order to determine static aerodynamic coefficients. All dimensions are in calibers and reference diameter is $154.7 \mathrm{~mm}$ [5]. The mass and inertia characteristics of the test projectile computed using the INVENTOR software.Table 1 shows the main data and initial firing conditionsof the unguided artillery projectile, reference area: $\mathrm{S}=$ $\pi \mathrm{d} 2 / 4$. 
TABLE I. MAIN DATA AND INITIAL FIRING CONDITIONS.

\begin{tabular}{|l|l|l|}
\hline Caliber & $\mathrm{D}$ & $0.1547 \mathrm{~m}$ \\
\hline Length & $\mathrm{L}$ & $0.702338 \mathrm{~m}$ \\
\hline Mass & $\mathrm{m}$ & $43 \mathrm{Kg}$ \\
\hline Center of Gravity from Nose & $\mathrm{X}_{\mathrm{CG}}$ & $0.438338 \mathrm{~m}$ \\
\hline Axial Moment of Inertia & $\mathrm{I}_{\mathrm{X}}$ & $0.1122 \mathrm{Kg} \cdot \mathrm{m}^{2}$ \\
\hline Lateral Moment of Inertia & $\mathrm{I}_{\mathrm{Y}}=\mathrm{I}_{\mathrm{Z}}$ & $1.1363 \mathrm{Kg} \cdot \mathrm{m}^{2}$ \\
\hline Muzzle Velocity & $\mathrm{V}_{0}$ & $692 \mathrm{~m} / \mathrm{sec}$ \\
\hline Wind Speed & $\mathrm{V}_{\mathrm{W}}$ & $0 \mathrm{~m} / \mathrm{sec}$ \\
\hline Firing Angle & $\theta_{0}$ & 44 degree \\
\hline
\end{tabular}

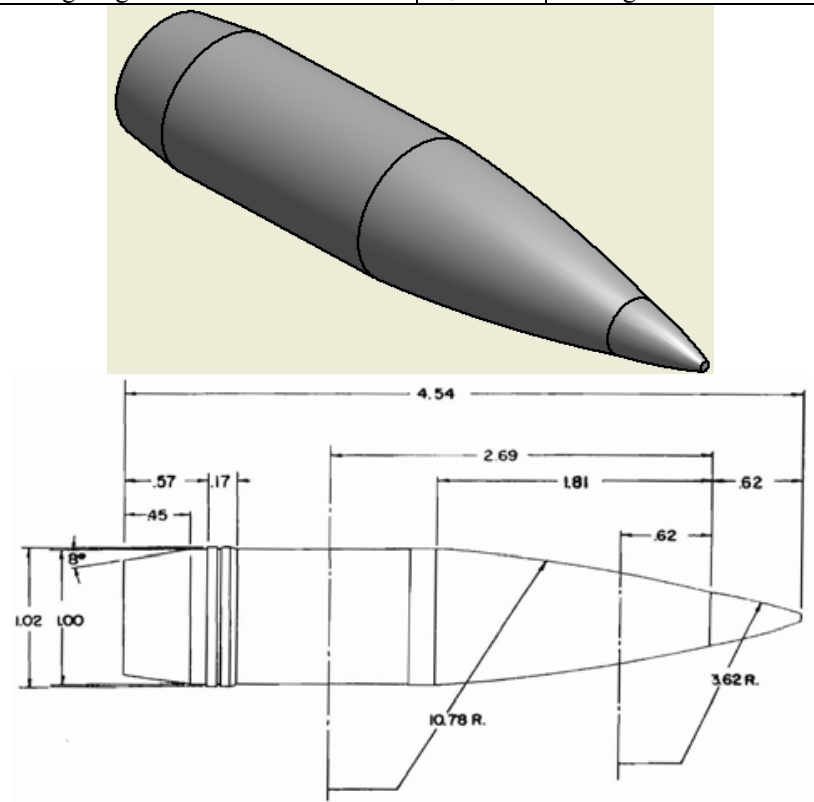

FIGURE I. TEST PROJECTILE SOLID MODEL AND MAIN DIMENSIONS

\section{B. Grid Generation}

The grids for the geometry investigated were obtained from ANSYS ICEM-CFD software as the numerical grids had been previously constructed. Quadrilateral cells were used in domain. The projectile contained hexahedral cells. The total number of mesh equals 346352 cells. The computational domain was extended to be 7 times diameter far from projectile base, 3 times diameter around the projectile, and 1 time diameter far from projectile nose as shown in fig. 2.

\section{Solver}

CFD is applied to determine the aerodynamic coefficients by using a commercial code called ANSYS FLUENT. The governing equation in this work is the full Navier-Stokes equation. The Turbulence model is the Spalart-Allmaras turbulent model. The model solves one transport equation for a quantity that is a modified form of the turbulent kinematics' viscosity and has provided better agreement with available experimental data. The convective term is approximated by second order Roe-FDS scheme. The second order central difference scheme is applied to pursuing numerical approximation of the viscous term. RungeKutta method was applied to step on time.

\section{Boundary Conditions}

The far field boundary is set to pressure far field density-based. This boundary condition is a characteristic type that allows the solver to determine the conditions at the far field boundary and either implicitly sets the boundary condition to free stream conditions. Free stream pressure and temperature are set to $1 \mathrm{~atm}$ and $300 \mathrm{~K}$, respectively. Density is then calculated from the perfect gas assumption. Angles of attack are taken as $\left(\alpha=0^{\circ}, 4^{\circ}, 8^{\circ}\right.$ and $\left.12^{\circ}\right)$ Mach numbers are taken as $(\mathrm{M}=0.6,0.9$, $1.2,1.5,2.0$, and 2.5 ). For projectile body, the boundary condition is set to be a non-slip wall.

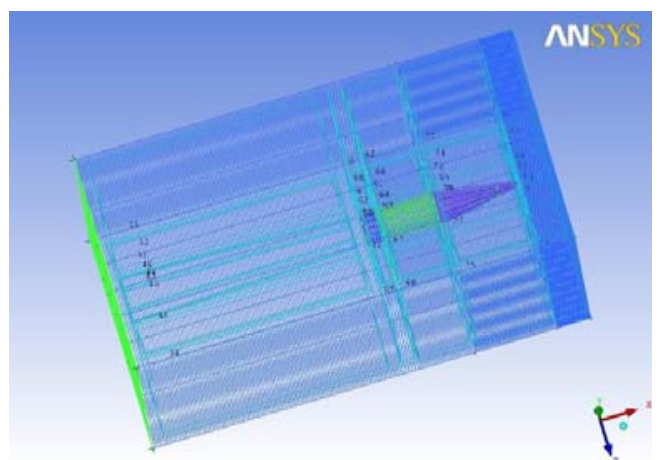

FIGURE II. MESHED PROJECTILE AND COMPUTATIONAL DOMAIN.

\section{E. Aerodynamic Coefficients}

Table 2 shows aerodynamic coefficient for studied projectile which are calculated using CFD code called ANSYS FLUENT14.5. See.

TABLE II. AERODYNAMIC COEFFICIENTS FOR THE TEST PROJECTILE.

\begin{tabular}{|c|c|c|c|c|c|}
\hline $\mathrm{M}$ & $\mathrm{C}_{\mathrm{D}}$ & $C_{L_{\alpha}}$ & $\mathrm{C}_{\mathrm{M}_{\alpha}}$ & $C_{N_{p \alpha}}$ & $\mathrm{C}_{\mathrm{l}_{p}}$ \\
\hline \hline 0.010 & 0.1455 & 1.6940 & 3.1000 & -0.7670 & -0.0230 \\
\hline 0.400 & 0.1455 & 1.6940 & 3.1371 & -0.7670 & -0.0230 \\
\hline 0.600 & 0.1455 & 1.6940 & 3.1870 & -0.7670 & -0.0230 \\
\hline 0.700 & 0.1425 & 1.7110 & 3.3727 & -0.7903 & -0.0226 \\
\hline 0.800 & 0.1396 & 1.7280 & 3.6856 & -0.8337 & -0.0217 \\
\hline 0.900 & 0.1366 & 1.7450 & 3.8510 & -0.8570 & -0.0210 \\
\hline 0.950 & 0.1773 & 1.8393 & 3.8355 & -0.8503 & -0.0208 \\
\hline 0.975 & 0.1977 & 1.8865 & 3.8179 & -0.8429 & -0.0207 \\
\hline 1.000 & 0.2181 & 1.9337 & 3.7951 & -0.8337 & -0.0205 \\
\hline 1.025 & 0.2384 & 1.9080 & 3.7683 & -0.8231 & -0.0204 \\
\hline 1.050 & 0.2588 & 2.0280 & 3.7386 & -0.8120 & -0.0203 \\
\hline 1.100 & 0.2995 & 2.1223 & 3.6750 & -0.7903 & -0.0202 \\
\hline 1.200 & 0.3810 & 2.3110 & 3.5620 & -0.7670 & -0.0200 \\
\hline 1.350 & 0.3646 & 2.3275 & 3.4192 & -0.7670 & -0.0200 \\
\hline 1.500 & 0.3481 & 2.3440 & 3.3310 & -0.7670 & -0.0200 \\
\hline 1.750 & 0.3206 & 2.3590 & 3.3125 & -0.7670 & -0.0205 \\
\hline 2.000 & 0.2931 & 2.3740 & 3.2990 & -0.7670 & -0.0210 \\
\hline 2.500 & 0.2452 & 2.5230 & 3.2300 & -0.7670 & -0.0200 \\
\hline
\end{tabular}

\section{EQUATIONS OF MOTION}

The modified point mass model gives an accurate approximation of the projectile's trajectory for all except the higher firing angles [6]. The equations of motion of the modified 
point mass model are derived to some assumption, the basic assumption is that the epicyclic pitching and yawing motion of the projectile is small everywhere along the trajectory. So the yaw and pitch moments will be neglected $(\mathrm{Cn} \cong 0, \mathrm{Cm} \cong 0)$. The following assumptions are also taken in the trajectory calculation:

- The trajectory is three-dimensional,

- Flat and non-rotating earth, and

- Constant gravity during whole the trajectory.

The modified point mass equations of motion are as follows:

$$
\begin{array}{r}
C_{D}=\left(C_{D_{0(M, \alpha)}}+C_{D_{\alpha^{2}}} \cdot \alpha^{2}\right)(1) \\
C_{Y}=\left(C_{Y_{\beta}} \cdot \beta+C_{N_{p \alpha}} \cdot \alpha \cdot\left(\frac{p \cdot L_{r e f}}{2 V_{a}}\right)\right)(2) \\
C_{L}=\left(C_{L_{\alpha}} \cdot \alpha+C_{L_{p_{\beta}}} \cdot \beta \cdot\left(\frac{p \cdot L_{r e f}}{2 V_{a}}\right)\right)(3) \\
C_{l}=\left(C_{l p(\dot{\phi})} \cdot\left(\frac{p \cdot L_{r e f}}{2 V_{a}}\right)\right)(4) \\
\left(C_{m} \cong 0, C_{n} \cong 0\right)(5)
\end{array}
$$

Where the gravitational acceleration in body reference frame will as follows by substituting $\phi=0$

$$
\left[\begin{array}{l}
g_{x} \\
g_{y} \\
g_{z}
\end{array}\right]_{B}=\left[\begin{array}{c}
-g \sin \theta \\
0 \\
g \cos \theta
\end{array}\right]
$$

Then the acceleration components in body reference frame are:

$$
\begin{array}{r}
\left(\frac{d V}{d t}\right)_{B}=\left(\frac{\overline{\mathrm{q}} \cdot S_{\mathrm{ref}}}{\mathrm{m}} \cdot \mathrm{C}_{\mathrm{D}}-\mathrm{g} \cdot \sin \theta\right) \cdot \hat{\imath}+\frac{\overline{\mathrm{q}} \cdot \mathrm{S}_{\mathrm{ref}}}{\mathrm{m}} \cdot\left(\mathrm{C}_{\mathrm{Y}_{\beta}} \cdot \beta+\mathrm{C}_{\mathrm{N}_{\mathrm{p} \alpha}} \cdot\right. \\
\left.\alpha \cdot\left(\frac{\mathrm{p} \cdot \mathrm{L}_{\mathrm{ref}}}{2 \mathrm{~V}_{\mathrm{a}}}\right)\right) \cdot \hat{\jmath}+\left(\frac{\overline{\mathrm{q}} \cdot \mathrm{S}_{\mathrm{ref}}}{\mathrm{m}} \cdot\left(\mathrm{C}_{\mathrm{L}_{\alpha}} \cdot \alpha+\mathrm{C}_{\mathrm{L}_{\mathrm{p}_{\beta}}} \cdot \beta \cdot\left(\frac{\mathrm{p} \cdot \mathrm{L}_{\mathrm{ref}}}{2 \mathrm{~V}_{\mathrm{a}}}\right)\right)+\mathrm{g} \cdot\right. \\
\cos \theta) \cdot \hat{\mathrm{k}}(7)
\end{array}
$$

The angular acceleration of the body about its axis of symmetry (spin angular acceleration) is given by [6]:

Where the aerodynamic angles are

$$
\frac{\mathrm{dp}}{\mathrm{dt}}=\frac{\mathrm{C}_{\mathrm{lp}} \cdot \rho \cdot \mathrm{V} \cdot \mathrm{p} \cdot \mathrm{L}_{\mathrm{ref}}^{2} \cdot \mathrm{S}_{\mathrm{ref}}}{4 \cdot \mathrm{I}_{\mathrm{XX}}}(8)
$$

Angle of attack

$$
\alpha=\tan ^{-1}\left(\frac{w}{u}\right)(9)
$$

$\mathrm{u}, \mathrm{v}$, and $\mathrm{w}$ are the body velocity components in the body reference frame.

The sideslip angle $\beta$ can be computed from the yaw of repose angle [7], where $\beta=\alpha_{R} \cdot \hat{\jmath}$

Where $\quad \alpha_{R}=\frac{8 \cdot p \cdot I_{X X}}{\pi \cdot \rho \cdot D^{2} \cdot L_{r e f} \cdot C_{M_{\alpha}} \cdot V^{4}}\left(\frac{d V}{d t} \times V\right)$ is the yaw of repose angle (total angle of attack) [8].

In [6] there is a good approximation for the yaw of repose angle which is:

$$
\alpha_{\mathrm{R}}=\frac{8 \cdot \mathrm{p} \cdot \mathrm{I}_{\mathrm{XX}}}{\pi \cdot \rho \cdot \mathrm{D}^{2} \cdot \mathrm{L}_{\mathrm{ref}} \cdot \mathrm{C}_{\mathrm{M}_{\alpha}} \cdot \mathrm{V}^{4}}(\mathrm{~g} \times \mathrm{V})
$$

Where

$$
\begin{aligned}
& \mathrm{g} \times \mathrm{V}=\left|\begin{array}{ccc}
\mathrm{i} & \mathrm{j} & \mathrm{k} \\
-\mathrm{g} \cdot \sin \theta & 0 & \mathrm{~g} \cdot \cos \theta \\
\mathrm{u} & \mathrm{v} & \mathrm{w}
\end{array}\right|=\left[\begin{array}{c}
-\mathrm{v} \cdot \cos \theta \\
\mathrm{w} \cdot \sin \theta+\mathrm{u} \cdot \cos \theta \\
-\mathrm{v} \cdot \sin \theta
\end{array}\right] \\
& \because \mathrm{v}, \mathrm{w}<<1, \text { then } \mathrm{v}, \mathrm{w} \cong 0, \mathrm{u} \cong \mathrm{v} \\
& \therefore \alpha_{\mathrm{R}}=\frac{8 \cdot \mathrm{I}_{\mathrm{XX}} \cdot \mathrm{p} \cdot \mathrm{g} \cdot \cos \theta}{\pi \cdot \rho \cdot \mathrm{D}^{2} \cdot \mathrm{L}_{\mathrm{ref}} \cdot \mathrm{C}_{\mathrm{M}_{\alpha}} \cdot \mathrm{v}^{3}} \cdot \hat{\jmath}
\end{aligned}
$$

The side slip angle

$$
\beta=\frac{8 \cdot \mathrm{IXX}_{\mathrm{XX}} \cdot \mathrm{p} \cdot \mathrm{g} \cdot \cos \theta}{\pi \cdot \rho \cdot \mathrm{D}^{2} \cdot \mathrm{L}_{\mathrm{ref}} \cdot \mathrm{C}_{\mathrm{M}_{\alpha}} \cdot \mathrm{V}^{3}}(10)
$$

The transformation matrix from body frame to earth frame is:

$$
[]_{\mathrm{E}}=\left[\begin{array}{ccc}
\cos \theta \cdot \cos \psi & -\sin \psi & \sin \theta \cdot \cos \psi \\
\cos \theta \cdot \sin \psi & \cos \psi & \sin \theta \cdot \sin \psi \\
-\sin \theta & 0 & \cos \theta
\end{array}\right] \cdot[]_{\mathrm{B}}
$$

In the modified point mass model, Euler angles method is not used to get the transformation matrix, but:

$$
\theta=\sin ^{-1}\left(\frac{-\mathrm{V}_{\mathrm{ze}}}{\mathrm{V}}\right) \text { and } \psi=\tan ^{-1}\left(\frac{\mathrm{V}_{\mathrm{ye}}}{\mathrm{V}_{\mathrm{xe}}}\right)
$$

Where: $V_{x e}, V_{y e}$ and $V_{z e}$ are the body velocities in earth reference frame.

\section{TRAJECTORY SIMULATION}

The presented modified point mass model is used to calculate the trajectory. Our investigated case corresponds to firing angle $\theta 0=44^{\circ}$ (corresponding to the maximum range in firing tables). Fig. 3 shows the spinning projectile trajectory at $\theta 0=44^{\circ}$. The figure show thesummit point $(5755.174 \mathrm{~m})$, maximum range (18447.245 m), andprojectile drift (386.931 m), which is to the right due to projectile high spin rate (spin stabilized projectile)while the. All values are non-dimensionalized by $\left(\frac{\mathrm{p} \cdot \mathrm{L}_{\mathrm{ref}}}{2 \mathrm{~V}_{\mathrm{a}}}\right)$.

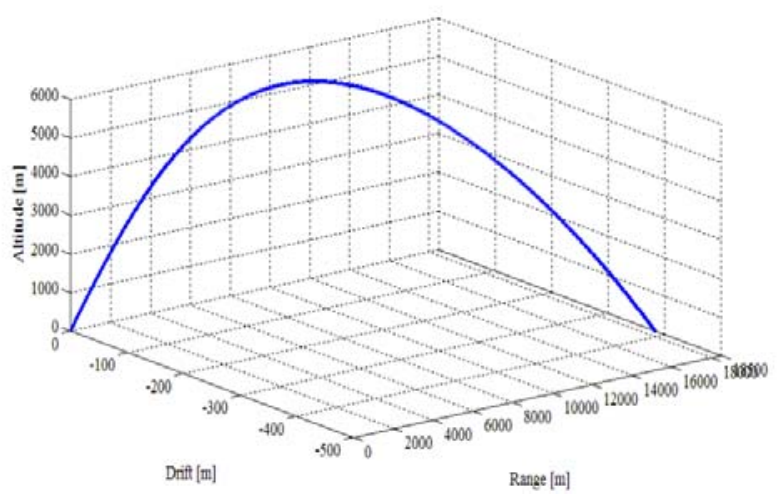

FIGURE III. UNGUIDED ARTILLERY PROJECTILE NOMINAL TRAJECTORY FOR $\Theta 0=44^{\circ}$.

\section{FIRING PRECISION}

Precision improvement has been done for a modified point mass model at firing angle $\theta 0=44^{\circ}$. Monte Carlo simulation was done randomly for 100 rounds as a method to improve the projectile precision. Monte Carlo method was used to find out 
the optimum value of circular error probable (CEP). In this work, we have been calculated CEP about the mean nominal point of impact with a simple estimator has been suggested by [9]. The models modified in the projectile simulation to include dispersion capabilities which are firing conditions, and projectile mass properties. Table 3 shows a set ofuncertainty parameters that have been used in this work. The limits of uncertainty parameters presented in table 3 are the variation range of the initial firing conditions (table 1), which have been implemented in to Monte Carlo method. Fig.4 $(a, b)$ shows CEP of projectile.

TABLE III. UNCERTAINTY PARAMETERS RANGE.

\begin{tabular}{|l|l|l|}
\hline Parameter Definition & $\begin{array}{l}\text { Uncertainty } \\
\text { Range }\end{array}$ & Units \\
\hline Projectile Mass & {$[-0.15,15]$} & Kg \\
\hline Axial Moment of Inertia & {$[-0.005,0.005]$} & Kg.m \\
\hline Lateral Moment of Inertia & {$[-0.05,0.05]$} & Kg.m \\
\hline Projectile Caliber & {$[-0.005,0.005]$} & $\mathrm{m}$ \\
\hline Projectile Muzzle Velocity & m/s \\
\hline Firing Angle & {$[-2,2]$} & degree \\
\hline Wind Direction at Zero Altitude & {$[-2,2]$} & degree \\
\hline Wind Speed at Zero Altitude & {$[-2,2]$} \\
\hline
\end{tabular}

(b) Mean of projectile drift

FIGURE IV. CEP OF UNGUIDED ARTILLERY PROJECTILE.

\section{CONCLUSION}

In the present work, CFD technique was used to predict aerodynamic coefficients of unguided projectile. Also prediction of modified point mass model trajectory was performed. The Turbulence model was the Spalart-Allmaras turbulent model. The convective term is approximated by second order Roe-FDS scheme. The second order central difference scheme is applied to pursuing numerical approximation of the viscous term. RungeKutta method was applied to step on time.Prediction of nominal trajectory and CEP of the unguided projectile was done by using MATLAB software with Monte Carlo simulation as a method to improve firing precision of the projectile.

\section{ACKNOWLEDGEMENTS}

This work supported by the Foundation of Key Laboratory of Transient Physics (9140C300205110C30), China.

\section{REFERENCES}

[1] Kokes J., Costello M., and Sahu J., "generating an Aerodynamic Model for Projectile flight simulation using Unsteady, Time Accurate Computational fluid Dynamics", U.S. Army Research Laboratory, Aberdeen Proving Ground, MD 21005-5066, September 2006.

[2] Gagnon E., and Lauzon M., "Course Correction Fuze Concept Analysis for In Service $155 \mathrm{~mm}$ Spin-Stabilized Gunnery Projectiles”, AIAA Guidance, Navigation and Control Conference and Exhibit, Honolulu, Hawaii, 18 - 21 August 2008.

[3] SAGHAFI F., and KHALILIDELSHAD M., "A Monte-Carlo Dispersion Analysis of a Rocket Flight Simulation Software", $17^{\text {th }}$ European Simulation Multi-Conference ESM2003, England, 9-11 June, 2003.

[4] Sahu, J., 1991. "Transonic Navier-Stokes computations for a spinning body of revolution", Tech. Rep. ARL-TR-3265, U.S. Army Research Laboratory.

[5] Robert L. McCoy, "Modern Exterior Ballistics", $4^{\text {th }}$ edition, ISBN-0-7643-0720-7, Schiffir Publishing Ltd., 1998.

[6] Calise, A. J., and El-Shirbiny, H. A., "An Analysis of Aerodynamic Control for Direct Fire Spinning Projectiles", Georgia Institute of Technology, AIAA 2001-4217, 2001.

[7] Arrow Tech Associates, "PRODAS, Technical Manual", Printed in U.S.A., 1993.

[8] Yaw of repose, http://www.nennstiel-ruprecht.de/bullfly/yawrepf.htm.

[9] Moranda, P.B., "Comparison of Estimates of Circular Probable Error", Journal of the American Statistical Association, Vol. 54, No. 288.

[10] (1959), pp. 794-800. 